\title{
Possible new ways in the pharmacological treatment of bipolar disorder and comorbid alcoholism
}

\author{
Jean-Michel Azorin' \\ Charles L Bowden ${ }^{2}$ \\ Ricardo P Garay ${ }^{3}$ \\ Giulio Perugi ${ }^{4}$ \\ Eduard Vieta ${ }^{5}$ \\ Allan H Young 6 \\ 'Department of Psychiatry, CHU \\ Sainte Marguerite, Marseilles, France; \\ ${ }^{2}$ Department of Psychiatry, University \\ of Texas Health Science Center, San \\ Antonio, TX, USA; ${ }^{3}$ CNRS-UMR 8I62, \\ Université Paris-Sud, and Hôpital \\ Marie Lannelongue, Le Plessis- \\ Robinson, France; ${ }^{4}$ Vincent $P$ Dole \\ Dual Diagnosis Team, Santa Chiara \\ and University Hospital, Department \\ of Psychiatry, University of Pisa, Italy; \\ ${ }^{5}$ Clinical Institute of Neuroscience, \\ Hospital Clinic, University of \\ Barcelona, IDIBAPS, CIBER-SAM, \\ Barcelona, Spain; ${ }^{6}$ Institute of Mental \\ Health, University of British Columbia, \\ Vancouver, Canada
}

Correspondence: Ricardo P Garay 46bis, rue du Maréchal Galliéni - 91360 Villemoisson-sur-Orge, France

Tel +33 I 69048034

Fax +33 I 69048034

Email ricardo.garay@orange.fr
This article was published in the following Dove Press journal:

Neuropsychiatric Disease and Treatment

26 February 2010

Number of times this article has been viewed

\begin{abstract}
About half of all bipolar patients have an alcohol abuse problem at some point of their lifetime. However, only one randomized, controlled trial of pharmacotherapy (valproate) in this patient population was published as of 2006. Therefore, we reviewed clinical trials in this indication of the last four years (using mood stabilizers, atypical antipsychotics, and other drugs). Priority was given to randomized trials, comparing drugs with placebo or active comparator. Published studies were found through systematic database search (PubMed, Scirus, EMBASE, Cochrane Library, Science Direct). In these last four years, the only randomized, clinically relevant study in bipolar patients with comorbid alcoholism is that of Brown and colleagues (2008) showing that quetiapine therapy decreased depressive symptoms in the early weeks of use, without modifying alcohol use. Several other open-label trials have been generally positive and support the efficacy and tolerability of agents from different classes in this patient population. Valproate efficacy to reduce excessive alcohol consumption in bipolar patients was confirmed and new controlled studies revealed its therapeutic benefit to prevent relapse in newly abstinent alcoholics and to improve alcohol hallucinosis. Topiramate deserves to be investigated in bipolar patients with comorbid alcoholism since this compound effectively improves physical health and quality of life of alcohol-dependent individuals. In conclusion, randomized, controlled research is still needed to provide guidelines for possible use of valproate and other agents in patients with a dual diagnosis of bipolar disorder and substance abuse or dependence.
\end{abstract}

Keywords: bipolar disease, alcohol, alcoholism, comorbidity, valproate

\section{Introduction}

In the US, almost half of all bipolar patients have an alcohol abuse problem at some point in their lifetime. ${ }^{1-3}$ Concurrent alcohol abuse disorders have been linked to severe disability, increased violence, increased hospitalization, and greater suicide risk. ${ }^{1-3}$ However, few treatment trials have been conducted in this population. In 2006, three reviews of the literature ${ }^{1-3}$ showed only one randomized, controlled trial of pharmacotherapy (valproate) and raised the hope of more studies coming in the near future. Given the importance of the subject, we review here the clinical trials published from 2006 to the present. Drugs reviewed belong to three therapeutic classes: mood stabilizers, atypical antipsychotics, and drugs specifically used for treating alcohol dependence. Readers interested in psychotherapeutic approaches can consult the recent studies by Weiss and colleagues ${ }^{4,5}$ and Farren and colleagues. ${ }^{6}$ Molecular mechanisms of bipolar disease and drug action were reviewed by Lan and colleagues, ${ }^{7} \mathrm{Kato},{ }^{8}$ and Catapano and Manji. ${ }^{9}$ 


\section{Methods}

\section{Search strategy}

We reviewed recent clinical trials (from the last four years) of efficacy and tolerability of drugs in bipolar disorder and comorbid alcoholism. A priority was given to randomized trials, comparing drugs with placebo or active comparators.

We compared the following keywords (as article title, when possible): "lithium", "anticonvulsants", "valproate", "lamotrigine", topiramate, "gabapentin", "atypical antipsychotics", "quetiapine”, “aripiprazole", "risperidone”, "olanzapine", "naltrexone", or "acamprosate" with: "bipolar" and/or "alcohol", and/or "alcoholism".

\section{Databases}

Published studies were found through systematic search of databases (PubMed, Scirus, EMBASE, Cochrane Library, Science Direct). We also searched the registers of: The Cochrane Central Register of Controlled Trials, ClinicalTrials.gov, Current Controlled Trials, International Clinical Registry Platform of the World Health Organization, CenterWatch, and Afssaps.

\section{Other sources}

We consulted the abstracts from recent Annual Meetings of the American Academy of Addiction Psychiatry (AAAP) and the American Psychiatric Association (APA). A reference to these abstracts is given when the studies were presented at meetings only. We also checked the references of articles and trials, and reviewed main psychiatric journals and guidelines for the treatment of patients with bipolar or substance use disorders. Finally, we contacted trial authors, other experts, and consulted the websites of pharmaceutical companies that market active compounds.

\section{Results}

Table 1 summarizes the results of recent clinical trials in bipolar disease with comorbid alcoholism.

\section{Lithium}

\section{Previous data}

In 1998, Geller and colleagues ${ }^{10}$ reported an advantage of lithium compared with placebo in improving mood symptoms and substance use in a small, six-week, double-blind study

Table I Recent clinical trials in bipolar disease with comorbid alcoholism

\begin{tabular}{|c|c|c|c|c|c|}
\hline Study & Design & Drug & Sample (n) & $\begin{array}{l}\text { Observation } \\
\text { period }\end{array}$ & Effect size \\
\hline Sattar ${ }^{16,32}$ & Open label trial & Valproate & $\begin{array}{l}20 \text { SUDP } \\
(\text { Alcohol } n=10)\end{array}$ & 24 weeks & $\begin{array}{l}\text { Halved both, SUD days (BS) } \\
\text { and YMRS score (BS) }\end{array}$ \\
\hline Reoux et al ${ }^{17^{*}}$ & $\begin{array}{l}\text { Double-blind, placebo- } \\
\text { controlled trial }\end{array}$ & $\begin{array}{l}\text { Valproate (V) } \\
\text { Placebo (P) }\end{array}$ & $\begin{array}{l}\text { I3 (5 HAP) } \\
14 \text { (7 HAP) }\end{array}$ & 12 weeks & $\begin{array}{l}\text { Relapses: } 0(\mathrm{~V}) \text { vs } \\
3 \text { (P) in HAP } \\
\text { patients (SS) }\end{array}$ \\
\hline Rubio et $\mathrm{a}^{22}$ & Open label trial & Lamotrigine & 28 & 24 weeks & $\begin{array}{l}30 \% \text { to } 70 \% \text { reduction in all } \\
\text { outcome measures (SS) }\end{array}$ \\
\hline Brown et $\mathrm{al}^{33}$ & $\begin{array}{l}\text { Randomized, double blind, } \\
\text { placebo-controlled }\end{array}$ & $\begin{array}{l}\text { Quetiapine (Q) } \\
\text { Placebo (P) }\end{array}$ & $\begin{array}{l}52 \\
50\end{array}$ & 12 weeks & $\begin{array}{l}\text { HRSD: }-10.1(\mathrm{~V}) \text { vs }-9.0(\mathrm{P}) \\
\text { (SS). NS for alcohol use }\end{array}$ \\
\hline Martinotti et $\mathrm{a}^{34}$ & Open label trial & Quetiapine & $\begin{array}{l}28 \mathrm{MDP} \\
(\mathrm{BP}=16)\end{array}$ & 16 weeks & $\begin{array}{l}\text { SS reductions in all alcohol } \\
\text { outcome measures (alcohol free } \\
\text { MDP }=43 \% \text { ) }\end{array}$ \\
\hline Davis et $\mathrm{al}^{36^{*}}$ & $\begin{array}{l}\text { Randomized, double blind, } \\
\text { comparative study }\end{array}$ & $\begin{array}{l}\text { Risperidone vs } \\
\text { Valproate }\end{array}$ & 30 & 12 weeks & $\begin{array}{l}\text { NS differences in alcohol } \\
\text { outcome measures }\end{array}$ \\
\hline Brown et $\mathrm{a}^{38}$ & Open label trial & Naltrexone & 34 & 16 weeks & $\begin{array}{l}\text { SS improvement in HRSD } \\
(-28 \%), \text { YMRS }(-34 \%) \text { and alcohol } \\
\text { outcome measures }(-50 \%)\end{array}$ \\
\hline Salloum et a ${ }^{39}$ & $\begin{array}{l}\text { Randomized, open label } \\
\text { trial }\end{array}$ & $\begin{array}{l}\text { Naltrexone/valproate vs } \\
\text { valproate alone }\end{array}$ & 21 & & $\begin{array}{l}\text { More abstinence with naltrexone/ } \\
\text { valproate }(7 I .4 \%) \text { than with } \\
\text { valproate alone }(43 \%)\end{array}$ \\
\hline Frye et $\mathrm{al}^{37 *}$ & $\begin{array}{l}\text { Single-blind randomized } \\
\text { trial }\end{array}$ & Valproate vs olanzapine & 50 & 52 weeks & $\begin{array}{l}\text { Valproate superior }(P=0.02) \\
\text { to olanzapine in reducing alcohol } \\
\text { relapse in women, but not in men }\end{array}$ \\
\hline
\end{tabular}

Notes: *Results reported in the form of a meeting abstract.

Abbreviations: SUDP, patients with substance use disorders; HAP, patients with high anxiety; HRSD, Hamilton Rating Scale for Depression; MDP, patients with mood disorders; BP, patients with bipolar disorders; SS, statistically significant; BS, borderline statistical significance; NS, nonstatistically significant. 
of 25 adolescents with bipolar disorder and secondary substance use.

\section{Recent data}

To our knowledge, no other randomized trial of lithium in bipolar disease with comorbid alcoholism followed the study of Geller and colleagues. ${ }^{10}$

\section{Anticonvulsants Valproate \\ Previous data}

In 1995, Brady and colleagues ${ }^{11,12}$ first reported preliminary evidence for the efficacy of valproate in the acute treatment of bipolar episodes complicated by concomitant substance dependence (see also Brady and colleagues ${ }^{13}$ ). In 2005, Salloum and colleagues ${ }^{14}$ published the results of a randomized, double blind trial where valproate was added to lithium in 59 alcoholic bipolar I patients. Twelve (44\%) of 27 subjects in the valproate group reported heavy drinking days compared with 17 (68\%) of 25 in the placebo group. Adding valproate to lithium halved excessive alcohol consumption (measured as the number of heavy drinking days and the number of drinks per heavy drinking day). ${ }^{14}$ Moreover, level of gamma-glutamyl transpeptidase, a consequence of recent alcohol use was significantly lower in the valproate group $(-19 \%)$ compared with the lithium plus placebo group. Manic and depressive symptoms improved equally in both groups. Based on these observations, ${ }^{11-14}$ the American Psychiatric Association (APA) supported the use of valproate to treat the comorbidity of bipolar disease with alcohol abuse. ${ }^{15}$

\section{Recent data}

In 2007, further evidence for valproate efficacy in reducing excessive alcohol consumption in bipolar patients was provided by Sattar, ${ }^{16}$ who conducted a 24 -week open study in 20 patients with bipolar disorder comorbid with alcohol dependence $(n=10)$ or other stimulant dependence $(n=10)$. Similarly to Salloum and colleagues, ${ }^{14}$ subjects halved the number of substance use days (17.1 vs 9.7 days) as compared with the month before valproate treatment, ${ }^{16}$ although the difference was of borderline statistical significance $(P=0.07)$. Patients tolerated valproate well with minimal reports of side effects and no liver toxicity was noted.

Reoux and colleagues ${ }^{17}$ recently found that valproate (extended release divalproex sodium) promotes abstinence in newly abstinent alcoholics with comorbid mood and anxiety disorders. These authors carried out a 12 week, double-blind placebo-controlled clinical trial of valproate in 32 of these patients. Patients with higher anxiety scores were less likely to experience alcohol dependence relapse if in the valproate treatment group $(P=0.017)$. In addition to promoting abstinence, valproate treatment improved psychiatric symptoms in alcohol dependent individuals with greater baseline psychiatric symptom severity, particularly mood and anxiety symptoms. ${ }^{17}$

\section{Side effects}

One concern with the use of valproate in actively drinking or recovering alcoholics is the potential for serious, although rare, hepatic and/or pancreatic side effects. ${ }^{18-21}$ As documented out by Frye and Salloum, ${ }^{1}$ none of the studies completed to date on valproate in alcohol dependence (withdrawal or relapse prevention) or in bipolar disorder with comorbid alcoholism have reported such serious adverse events. Most of these studies have reported a decrease, rather than an increase, in liver function tests, mostly due to a decrease in alcohol use. However, care should be taken before a conclusion is reached because the sample sizes of these treatment studies were too small to find rare but severe side effects.

\section{Lamotrigine}

To our knowledge, no randomized studies of lamotrigine in bipolar disease with comorbid alcoholism have been conducted so far. In 2006, Rubio and colleagues ${ }^{22}$ reported the results of an open-label trial of lamotrigine in 18 men and 10 women diagnosed with alcohol dependence and bipolar disorder I $(n=21)$ or bipolar disorder II $(n=7)$, with a mean age of 36.5 years. Lamotrigine was added to the existing medication regimens at a dose of $25 \mathrm{mg} /$ day and titrated to a maximum dose of $300 \mathrm{mg} /$ day. The concentration of carbohydratedeficient transferrin (CDT) was used as an indirect measure of alcohol consumption. Statistically significant decreases were found for: CDT $(-40 \%, P<0.001)$, Visual Analog Scale for Craving (VASC; $-32.5 \%, P<0.01$ ), drinks per week $(-67.7 \%, P<0.01)$, Hamilton Rating Scale for Depression (HRSD; $-31.4 \%, P<0.01$ ), Young Mania Rating Scale (YMRS; $-40.8 \%, P<0.001$ ) and Brief Psychiatric Rating Scale (BPRS; $-54.4 \%, P<0.01)$ scores. Lamotrigine was well tolerated with no dropout subjects due to adverse events.

\section{Topiramate}

No randomized studies of topiramate in bipolar disease with comorbid alcoholism were found in the literature.

\section{Previous data}

In 2002, Guille and $\mathrm{Sachs}^{23}$ reported that topiramate improved a comorbid alcohol use abuse condition in four out of seven highly refractory bipolar patients. In 2005, Huguelet and 
Morand-Collomb ${ }^{24}$ reported the case of a 41-year-old bipolar patient suffering a severe comorbidity with alcoholism, where topiramate treatment allowed him to decrease his alcohol intake to an acceptable level.

\section{Recent data}

To our knowledge, no studies of topiramate in bipolar disease with comorbid alcoholism have been reported in the literature recently.

\section{Gabapentin}

No randomized studies of gabapentin in bipolar disease with comorbid alcoholism were found in the literature.

\section{Previous data}

Perugi and colleagues ${ }^{25}$ evaluated the effectiveness of gabapentin as adjunctive treatment in a sample of 43 subjects with bipolar disorder who were resistant to standard mood stabilizers. Gabapentin was administered as an adjunctive treatment for an eight-week period in combination with other mood stabilizers, benzodiazepines, antidepressants, and neuroleptics. Logistical regression analysis showed that the presence of alcohol abuse was associated with positive response.

To our knowledge, no other trials of gabapentin in bipolar disease with comorbid alcoholism have been published.

\section{Atypical antipsychotics Quetiapine}

\section{Previous data}

Quetiapine is an atypical antipsychotic medication that is used to treat the mood symptoms of bipolar disorder. ${ }^{26-28}$ The pilot studies of Brown and colleagues ${ }^{29-31}$ in small numbers of dual-diagnosis patients $(n=17-24)$ and that of Sattar and colleagues $^{32}$ in nine alcoholic patients with nonpsychotic anxiety suggested that quetiapine can reduce alcohol use, anxiety, and cravings for alcohol.

\section{Recent data}

In 2008, Brown and colleagues ${ }^{33}$ reported the results of a randomized, double-blind, placebo-controlled trial of quetiapine (add-on therapy) in 115 outpatients with bipolar disorder and alcohol abuse or dependence. Patients were randomly assigned to 12 weeks of quetiapine (titrated to $600 \mathrm{mg} /$ day) add-on therapy or placebo. One hundred two participants (49\% with bipolar I disorder, 82\% depressed, and $97 \%$ with alcohol dependence) returned for at least one postbaseline assessment and were used in the random regression analysis. Baseline concomitant medications and changes in concomitant medications did not differ significantly between quetiapine (antidepressants: $38.5 \%$; anticonvulsants: 25\%; lithium: 13.5\%) and placebo (antidepressants: 28\%; anticonlvulsants: 18\%; lithium: 4\%) groups. No differences were found between the quetiapine add-on group and the placebo group on the primary outcome measures of alcohol use or the YMRS. However, scores on the HRSD decreased significantly more in the quetiapine than in the placebo group $(P<0.05)$. The between-group difference was largely due to differences in HRSD scores during the first six weeks of the trial, with the placebo group showing greater improvement during the second half of the trial. ${ }^{33}$

Martinotti and colleagues ${ }^{34}$ recently conducted an openlabel 16 week study of quetiapine on 28 alcohol-dependent subjects with high levels of mood and behavioral instability, including 16 patients with bipolar disorders. Quetiapine significantly decreased alcohol consumption (43\% of patients remained totally alcohol-free for the duration of the study), craving for alcohol, and psychiatric symptoms intensity (HDRS and BPRS), maintaining a good level of tolerability. ${ }^{34}$

\section{Aripiprazole}

Aripiprazole is another atypical antipsychotic used to treat mainly manic symptoms of bipolar disorder. To our knowledge, no randomized studies of aripiprazole in bipolar disorders with comorbid alcoholism have been conducted so far.

\section{Previous data}

In 2005, Brown and colleagues ${ }^{35}$ conducted an open-label, pilot trial with aripiprazole in 20 antipsychotic-treated patients with bipolar or schizoaffective disorder and current substance abuse. Patients were switched to open-label aripiprazole using an overlap and taper method. Psychiatric symptoms, side effects, and substance use and craving were assessed over 12 weeks. Significant baseline-to-exit improvement in $\operatorname{HRSD}(P=0.002)$, YMRS $(P=0.021)$, and BPRS $(P=0.000)$ scores were observed without a significant change in antipsychotic-induced side effect scales. In 17 participants with current alcohol dependence, significant reductions in dollars spent on alcohol $(P=0.042)$ and alcohol craving $(P=0.003)$ were found. In nine participants with cocainerelated disorders, significant reductions in cocaine craving $(P=0.014)$, but not use, were found.

\section{Recent data}

To our knowledge, no other studies of aripiprazole in bipolar disorders with comorbid alcoholism were conducted since the one of Brown and colleagues. ${ }^{35}$ 


\section{Risperidone}

Davis and colleagues ${ }^{36}$ recently conducted a randomized, double blind 12-week trial with valproate extended release (ER) vs. risperidone monotherapy in 30 bipolar I and II patients with active substance use disorder (SUD) within the past 30 days. No significant differences between groups were found for the number of days until heavy SUD relapse, time to relapse, percentage days of SUD use, or percentage days sober.

\section{Olanzapine}

In 2006 , Frye and colleagues ${ }^{37}$ conducted a 52-week singleblind randomized study of valproate versus olanzapine for alcohol abuse relapse prevention in 50 actively drinking bipolar disease patients. Valproate was found superior $(P=0.02)$ to olanzapine in reducing the rate of relapse to alcoholism (defined as return to hazardous drinking) in women, although not in men. ${ }^{37}$

\section{Drugs specifically used for treating alcohol dependence \\ Naltrexone}

Naltrexone is effective for alcohol dependence, but its safety and efficacy are not established in patients with bipolar disorder and alcohol dependence. Brown and colleagues ${ }^{38}$ recently reported the results of a 16-week, open-label, add-on pilot study of naltrexone conducted in 34 outpatients with bipolar disorder and alcohol dependence. Assessments included the 17-item HRSD, YMRS, BPRS and an alcohol-craving scale. Alcohol use was quantified. Significant improvement was observed in the HRSD (-28\%), YMRS (-34\%), number of drinks in the past two weeks $(-50 \%)$, and alcohol craving $(-49 \%)$. Naltrexone was well tolerated.

Salloum and colleagues ${ }^{39}$ conducted a randomized, open-label study to examine the utility of combined pharmacotherapy of valproate/naltrexone vs valproate only in decreasing alcohol use in patients with comorbid bipolar disorder and alcohol dependence. Twenty-one subjects were included and followed for eight weeks. All but one (86\%) of the valproate/naltrexone group completed the study as opposed to three $(43 \%)$ of the valproate-only group. The majority 5/7 (71.4\%) of the combined group subjects maintained abstinence throughout the study compared to $3 / 7$ $(43 \%)$ in the valproate group. The valproate/naltrexone group compared to the valproate-only group had: (i) an advantage in percentage days abstinent, (ii) a somewhat lower percentage of heavy drinking, and (iii) an advantage on final outcomes for alcohol craving, depressive symptoms, sleep disturbance, and functioning. ${ }^{39}$

\section{Other drugs used for treating alcohol dependence}

To our knowledge, no trials of acamprosate or other drugs used for treating alcohol dependence in bipolar disease with comorbid alcoholism have been published.

\section{Discussion}

The treatment of patients with bipolar disorder and alcohol use disorder is a major public health concern. However, few well designed clinical trials have been conducted in this population. Indeed, since Salloum and colleagues ${ }^{14}$ reported that adjunctive valproate reduces excessive alcohol consumption in bipolar patients, the only other randomized study with a clinically important result is that quetiapine therapy was associated with a statistically significant decrease in depressive symptoms, at least in the early weeks of use, but not alcohol use, in patients with bipolar disorder and alcohol dependence. ${ }^{33}$

The optimal therapeutic goals of excessive alcohol drinking are alcohol withdrawal coupled with relapse prevention. Well controlled trials in alcoholic patients (mostly without bipolar disease) showed that valproate is of therapeutic benefit in both alcohol withdrawal and relapse prevention. These results deserve to be mentioned since they can explain, at least in part, the therapeutic benefit of valproate in bipolar disease with comorbid alcoholism.

\section{Alcohol withdrawal}

Reoux and colleagues ${ }^{40}$ conducted a randomized, doubleblind, placebo-controlled trial of valproate in 36 hospitalized patients experiencing moderate alcohol withdrawal. All subjects received a baseline dose of oxazepam and had additional oxazepam available as a rescue medication. Valproate significantly improved alcohol withdrawal course and significantly reduced the use of oxazepam. Group differences seemed primarily driven by those subjects who experienced symptoms above threshold level after 12 hours. The progression in severity of withdrawal symptoms was also significantly greater in the placebo group.

\section{Relapse prevention}

An open randomized trial pilot study by Longo and colleagues ${ }^{41}$ suggested relapse prevention by valproate in 16 alcohol-dependent patients randomized to receive a standard benzodiazepine detoxification, valproate detoxification, or valproate detoxification with the maintenance treatment. Symptom reduction occurred more rapidly and consistently in the valproate treated patients than in the benzodiazepine 
control group, and at six-week follow up a greater percentage of patients in the valproate maintenance group were completely abstinent than either detox-only group.

\section{Alcohol hallucinosis}

In 2008, Aliyev and Aliyev ${ }^{42}$ reported the results of a 10-day randomized, double-blind, placebo-controlled study of valproate in 40 patients with acute alcohol hallucinosis. Patients were randomized to valproate $3000 \mathrm{mg} /$ day $(\mathrm{n}=20)$ or placebo $(n=20)$. Valproate-treated patients improved significantly more than placebo-treated patients in Clinical Global Improvement (CGI; $P<0.001$ ) and in Positive and Negative Syndrome Scale subscale for verbal hallucinosis (PANSS; $P<0.001$ ).

Although most studies of valproate in bipolar disorder with comorbid alcoholism or in alcohol dependence have reported improvement rather than worsening in liver function tests, for the present, when valproate is employed in patients with bipolar disorder comorbid with alcohol dependence, hepatic function should be assessed prior to the start of the treatment and at regular intervals thereafter and patients should monitoring for symptoms suggestive of liver toxicity. Due to the risks of fetal abnormalities from first trimester use of valproate, specialist advice is recommended when considering valproate use in women of child-bearing age.

Johnson and colleagues ${ }^{43,44}$ recently found that topiramate was efficient in reducing alcohol consumption in alcoholdependent subjects. These authors conducted a 17-site, 14-week, double-blind, randomized controlled trial of topiramate (up to $300 \mathrm{mg} /$ day) vs placebo in 371 alcohol-dependent subjects (without a current Axis I psychiatric diagnosis on the $D S M-I V$ other than alcohol, nicotine, or caffeine dependence) who received weekly adherence enhancement therapy. ${ }^{43,44}$ Treating all dropouts as relapse to baseline, topiramate was more efficacious than placebo at reducing the percentage of heavy drinking days from baseline to week $14 .{ }^{43}$ Moreover, topiramate was more efficacious than placebo in reducing liver enzyme levels. ${ }^{44}$ Topiramate compared with placebo, significantly decreased obsessional thoughts and compulsions about using alcohol, increased subjects' psychosocial well-being, and improved some aspects of quality of life, thereby diminishing the risk of relapse and longer-term negative outcomes. ${ }^{44}$ Conversely, four randomized, placebocontrolled trials of topiramate monotherapy were recently conducted in adults with acute manic or mixed episodes of bipolar I disorder. ${ }^{45}$ These trials showed no efficacy of topiramate against mania exacerbation or treatment-emergent depression. ${ }^{45}$
Given the promising results of the well-controlled trial of topiramate in alcohol-dependent individuals by Johnson and colleagues $^{43,44}$ (improvement of physical health and quality of life with topiramate treatment) this compound deserves to be investigated in bipolar disorder and alcohol dependence. The therapeutic benefit of topiramate in alcohol-dependence may be due to its anticonvulsant properties since other controlled studies revealed that valproate is of therapeutic benefit in acute alcohol withdrawal, ${ }^{40}$ that it prevents relapse in newly abstinent alcoholics ${ }^{17}$ and improves alcohol hallucinosis. ${ }^{42}$ Moreover, carbamazepine seems also effective to reduce alcohol withdrawal symptoms and prevent relapse. ${ }^{1}$

A randomized, double-blind, placebo-controlled trial of gabapentin in 90 alcohol-dependent subjects ${ }^{46}$ showed a significant reduction in both number of drinks per day and mean percentage of heavy drinking days, and an increase in the percentage of days of abstinence, compared to the placebo group. Conversely, the few randomized controlled trials designed to investigate the efficacy of gabapentin in treating bipolar disorder have concluded that there is no significant difference in the effects of the drug compared with placebo. ${ }^{47}$ This may explain why the preliminary study in 2002 by Perugi and colleagues ${ }^{25}$ in bipolar alcoholic patients was not followed by others.

The open label trials of Brown and colleagues ${ }^{38}$ and Salloum and colleagues ${ }^{39}$ suggest that added naltrexone is effective against alcohol use disorders in bipolar patients. Therefore, well controlled studies are required to further investigate the efficacy of naltrexone, alone or in combination with mood stabilizers.

Martinotti and colleagues ${ }^{48}$ showed that aripiprazole is as efficient as naltrexone in reducing alcohol use in alcoholdependent subjects. As for craving scores, patients treated with naltrexone showed a better outcome. ${ }^{48}$ Moreover, Anton and colleagues ${ }^{49}$ found more positive subjective treatment effects and less overall severity of alcohol dependence in subjects treated with aripiprazole as compared with placebo. Finally, Brown and colleagues ${ }^{35}$ found significant reductions in dollars spent on alcohol and alcohol craving by aripiprazole in bipolar (or schizoaffective) alcoholic patients. These results suggest that the efficacy of aripiprazole in alcohol use disorders of bipolar patients should be further investigated.

The preliminary small study with lithium reported by Geller and colleagues ${ }^{10}$ in 1998 was not followed by other studies in larger number of subjects. One reason can be that lithium carbonate was found ineffective in decreasing alcohol consumption in a large multicenter, double-blind, placebocontrolled Veterans Affairs trial. ${ }^{50}$ This study, conducted 
in 457 male alcoholics either without depression or with a history of major depression, current major depression, or mood disorder found no significant differences between alcoholics who took lithium and those who took placebo for the following outcome measures: number of alcoholics abstinent, number of days of drinking, number of alcohol-related hospitalizations, changes in rating of severity of alcoholism, and change in severity of depression. ${ }^{50}$ In this study, lithium treatment did not affect the course of alcoholism in either depressed or nondepressed alcoholics. ${ }^{50}$

Another reason explaining the lack of recent lithium trials in bipolar disease with comorbid alcoholism may be that lithium is often ineffective in bipolar variants such as dysphoric, mixed, or rapid cycling, which are overrepresented among bipolar alcoholic patients. ${ }^{14,51}$

Understanding the molecular mechanisms of disease strongly helps the design of new pharmacological agents. In the past, some reports suggested that a gammaaminobutyric acid (GABA) deficit was involved in the pathogenesis of both bipolar disorder ${ }^{52,53}$ and alcoholism ${ }^{54}$ (and valproate increases central GABAergic activity ${ }^{55,56}$ ), but such studies are no longer conducted. Indeed, multiple neurotransmitter and neuropeptide $\mathrm{G}$ protein-coupled receptors (in frontal cortex and limbic-related regions, such as the hippocampus, hypothalamus, and brainstem) likely underly the complex clinical picture of bipolar disorder. ${ }^{9}$ Moreover, the relation with the biochemical and physiopathological mechanisms of alcoholism is unclear. Valproate or quetiapine mechanisms in bipolar disorder with comorbid alcoholism remain as open question which deserves further investigation.

Patients who show response to a certain treatment may represent a genetically more homogeneous subgroup of bipolar disorders particularly if this subgroup is characterized by specific comorbidity (as addiction). Association and linkage studies of candidate genes involved in GABAergic neurotransmission in valproate-responsive alcoholics/bipolar disorders should be developed in the future.

\section{Advances in clinical and epidemiological aspects}

Although the clinical and epidemiological aspects of bipolar disorder in comorbidity with alcoholism are beyond the scope of this review, recent advances in such areas can be useful to design future trials. Of particular interest are studies investigating patient subtypes and their therapeutic responses. Pacchiaroti and colleagues ${ }^{57}$ recently reported that bipolar patients with bipolar disorder I or II whose mood symptomatology onset was preceded by substance/alcohol use $(n=145)$ showed fewer total hypomanic and depressive episodes and were poorly compliant to treatment, as compared with bipolar patients whose first mood episode was unrelated to substance use $(n=144)$. The authors concluded that bipolar disorder preceded by substance misuse may represent a clinically milder subtype of bipolar illness and might be more early targeted by primary prevention with programmes focused on substance misuse. ${ }^{57}$

Haro and colleagues ${ }^{58}$ identified three groups of patients with acute mania: "typical mania" (59\% of patients); "psychotic mania" (27\%) with more severe mania and presence of psychotic symptoms; and "dual mania" (13\%) with a high proportion of substance abuse. Psychotic and dual mania predicted poorer outcome in terms of psychosis comorbidity and overall bipolar and mania severity, while dual mania additionally predicted poorer outcome of alcohol and substance abuse. ${ }^{59}$ Worse social outcomes were observed for both dual and psychotic mania. ${ }^{59}$

In 2007, Merikangas and colleagues ${ }^{60}$ reported the first prevalence estimates of the bipolar spectrum in a probability sample of the United States. Lifetime (and 12-month) prevalence estimates were $1.0 \%$ for bipolar disorder I, 1.1\% for bipolar disorder II, and $2.4 \%$ for subthreshold bipolar disorder. ${ }^{60}$ Most bipolar patients received lifetime professional treatment for emotional problems, but use of antimanic medication was uncommon, especially in general medical settings and subthreshold bipolar disorder. ${ }^{60}$

In 2008, Angst and associates ${ }^{61}$ estimated the respective risks posed by the different bipolar subtypes for the subsequent development of substance use disorders. Six waves of direct diagnostic interviews were administered to a sample of 591 young adults during a 20 -year period. Individuals having manic symptoms were at significantly greater risk for the later onset of alcohol abuse/dependence, cannabis use and abuse/ dependence, and benzodiazepine use and abuse/dependence. Bipolar II disorder predicted both alcohol abuse/dependence and benzodiazepine use and abuse/dependence. In contrast, major depression was predictive only of later benzodiazepine abuse/dependence.

Finally, it is important to recall that bipolar disorder is frequently underdiagnosed in the clinical population, leading to overuse of antidepressants and underuse of mood stabilizers. Recently, Albanese and colleagues ${ }^{62}$ reported that bipolar disorders are frequently underdiagnosed in substancedependent subjects. These authors found that bipolar disorder had not been previously diagnosed in approximately $50 \%$ of a sample of Caucasian males in a substance abuse population 
Table 2 Recommendations for the management of bipolar disorder in comorbidity with alcoholism ${ }^{63}$

- In case of alcohol abuse, reduce alcohol consumption to normal when possible. In case of failure or in case of alcohol-dependence, proceed to alcohol withdrawal.

- Following alcohol withdrawal, alcohol-dependence and bipolar disorder should be simultaneously treated. Use valproate as first treatment choice.

- Inform the patient about the interaction between alcoholism and bipolar disorder, insisting about the depressive risk.

- Rationalize the myth of alcohol as auto-medication. ${ }^{63}$

- Provide psycho-education about situations favoring mood disorder episodes or substance use.

- Evaluate treatment discontinuation or misuse.

who were diagnosed with bipolar disorder upon admission to an inpatient substance abuse program.

\section{Guidelines and patient management}

Based on the results from the study of Salloum and colleagues,,$^{14}$ the APA supported the use of valproate to treat the comorbidity of bipolar disease with alcohol abuse. ${ }^{15}$ However, due to the relative absence of clinical guidelines on patient selection and implementation of regimens, clear guidelines and recommendations are lacking. Based on published data and personal experience, Brousse and colleagues ${ }^{63}$ recently suggested tentative treatment guidelines. Table 2 summarizes such recommendations.

When possible, alcohol withdrawal without relapse is the therapeutic goal..$^{63}$ Abstinence is recommended when starting a treatment with mood stabilizer in a bipolar patient undergoing excessive alcohol drinking, particularly when the patient presents with mood symptoms. If possible, mood stabilizer treatment should be initiated under hospital control, until mood stabilization (around 1 month) and/or relapse prevention (around 6 months) is achieved. Finally, psychoeducation should be given about both alcohol dependence and bipolar disorders and, their complex interaction, including the dangers consequent to alcohol abuse and symptoms of relapse. ${ }^{63}$

\section{Conclusions and future directions}

In these last three years, the only randomized, clinically relevant study in bipolar patients with comorbid alcoholism is that of Brown and colleagues ${ }^{33}$ showing that quetiapine therapy decreased depressive symptoms in the early weeks of use, without modifying alcohol use. Valproate efficacy to reduce excessive alcohol consumption in bipolar patients ${ }^{14}$ was confirmed ${ }^{16}$ and new controlled studies revealed its therapeutic benefit to prevent relapse in newly abstinent alcoholics ${ }^{17}$ and to improve alcohol hallucinosis. ${ }^{42}$

Several compounds deserve to be investigated for their efficacy to reduce alcohol use disorders in bipolar patients:

- Topiramate. This compound effectively improves physical health and quality of life of alcohol-dependent individuals..$^{43,44}$ Moreover, a pilot study ${ }^{23}$ and a case repor $^{24}$ suggests its efficacy to reduce alcohol use disorders in bipolar patients.

- Naltrexone. Well controlled studies are required to further investigate the efficacy of naltrexone, alone or in combination with mood stabilizers, against alcohol use disorders in bipolar patients. ${ }^{38,39}$

- Aripiprazole. Aripiprazole seems efficient in reducing alcohol use disorders in alcohol-dependent subjects ${ }^{48,49}$ and even in bipolar patients. This should be confirmed in well controlled trials.

While the results have been generally positive and support the efficacy and tolerability of several agents from different classes in patients with a dual diagnosis of bipolar disorder and substance abuse or dependence, randomized, controlled research is needed to confirm these findings and provide conclusive results and guidelines for possible use of the agents.

\section{Disclosures}

The authors report no conflicts of interest in this work.

\section{References}

1. Frye MA, Salloum IM. Bipolar disorder and comorbid alcoholism: prevalence rate and treatment considerations. Bipolar Disord. 2006;8:677-685.

2. Vornik LA, Brown ES. Management of comorbid bipolar disorder and substance abuse. J Clin Psychiatry. 2006;67:24-30.

3. Brown ES. Management of comorbid bipolar disorder and substance abuse. J Clin Psychiatry. 2006;67(Suppl 7):24-30.

4. Weiss RD. Treating patients with bipolar disorder and substance dependence: Lessons learned. J Subst Abuse Treat. 2004;27: 307-312.

5. Weiss RD, Griffin ML, Jaffee WB, et al. A “community-friendly" version of integrated group therapy for patients with bipolar disorder and substance dependence: A randomized controlled trial. Drug Alcohol Depend. 2009;104:212-219.

6. Farren CK, McElroy S. Treatment response of bipolar and unipolar alcoholics to an inpatient dual diagnosis program. J Affect Disord. 2008; 106:265-272.

7. Lan MJ, McLoughlin GA, Griffin JL, et al. Metabonomic analysis identifies molecular changes associated with the pathophysiology and drug treatment of bipolar disorder. Mol Psychiatry. 2008;14:269-279.

8. Kato T. Molecular neurobiology of bipolar disorder: a disease of 'moodstabilizing neurons'? Trends Neurosci. 2008;31:495-503. 
9. Catapano LA, Manji HK. G protein-coupled receptors in major psychiatric disorders. Biochim Biophys Acta. 2007;1768:976-993.

10. Geller B, Cooper TB, Sun K, et al. Double blind and placebocontrolled study of lithium for adolescent bipolar disorders with secondary substance dependency. JAm Acad Child Adolesc Psychiatry. 1998;37:171-178

11. Brady KT, Sonne SC. The relationship between substance abuse and bipolar disorder. J Clin Psychiatry. 1995;56(Suppl 3):19-24.

12. Brady KT, Sonne SC, Anton R, Ballenger JC. Valproate in the treatment of acute bipolar affective episodes complicated by substance abuse: a pilot study. J Clin Psychiatry. 1995;56:118-121.

13. Brady KT, Myrick H, Henderson S, Coffey SF. The use of divalproex in alcohol relapse prevention: a pilot study. Drug Alcohol Depend. 2002;67:323-330.

14. Salloum IM, Cornelius JR, Daley DC, Kirisci L, Himmelhoch JM, Thase ME. Efficacy of valproate maintenance in patients with bipolar disorder and alcoholism: a double-blind placebo-controlled study. Arch Gen Psychiatry. 2005;62:37-45.

15. American Psychiatric Association. Practice guideline for the treatment of patients with substance use disorders, 2nd edition. 2006. Available from: http://wwwpsychorg/psych_pract/treatg/pg/prac_guide.cfm. Accessed on August 10, 2009.

16. Sattar SP. Valproate in the treatment of bipolar disorder and comorbid substance abuse: a 24-week open lable trial. Biol Psychiatry. 2007;61:46S.

17. Reoux JP, Malte CA, Farr CL, Ferguson LC, Saxon AJ, editors. Controlled trial of extended release divalproex sodium in alcohol dependent patients with subsyndromal psychiatric symptoms. 18Th annual meeting and symposium of the American Academy of Addiction Psychiatry (AAAP); 2007; Hotel Del Coronado, Coronado, CA, USA.

18. Bryant AE III, Dreifuss FE. Valproic acid hepatic fatalities. III. US experience since 1986. Neurology. 1996;46:465-469.

19. Jimenez-Rodriguezvila M, Caro-Patón A, Conde M, et al. Side-effects of sodium valproate, mainly related to its hepatic and pancreatic toxicity. Int J Clin Pharmacol Res. 1986;6:217-224.

20. Dreifuss FE, Santilli N, Langer DH, Sweeney KP, Moline KA, Menander KB. Valproic acid hepatic fatalities: a retrospective review. Neurology. 1987;37:379-385.

21. Dreifuss FE, Langer DH. Hepatic considerations in the use of antiepileptic drugs. Epilepsia. 1987;28(Suppl 2):S23-S29.

22. Rubio G, López-Muñoz F, Alamo C. Effects of lamotrigine in patients with bipolar disorder and alcohol dependence. Bipolar Disord. 2006;8:283-293.

23. Guille C, Sachs G. Clinical outcome of adjunctive topiramate treatment in a sample of refractory bipolar patients with comorbid conditions. Prog Neuropsychopharmacol Biol Psychiatry. 2002;26:1035-1039.

24. Huguelet P, Morand-Collomb S. Effect of topiramate augmentation on two patients suffering from schizophrenia or bipolar disorder with comorbid alcohol abuse. Pharmacol Res. 2005;52:392-394.

25. Perugi G, Toni $\mathrm{C}$, Frare F, et al. Effectiveness of adjunctive gabapentin in resistant bipolar disorder: is it due to anxious-alcohol abuse comorbidity? J Clin Psychopharmacol. 2002;22:584-591.

26. Vieta E, Calabrese JR, Goikolea JM, Raines S, Macfadden W. Quetiapine monotherapy in the treatment of patients with bipolar I or II depression and a rapid-cycling disease course: a randomized, doubleblind, placebo-controlled study. Bipolar Disord. 2007;9:413-425.

27. Calabrese JR, Keck PE Jr, Macfadden W, et al. A randomized, doubleblind, placebo-controlled trial of quetiapine in the treatment of bipolar I or II depression. Am J Psychiatry. 2005;162:1351-1360.

28. Thase ME, Macfadden W, Weisler RH, et al; BOLDER II Study Group. Efficacy of quetiapine monotherapy in bipolar I and II depression: a double-blind, placebo-controlled study (the BOLDER II study). $J$ Clin Psychopharmacol. 2006;26:600-609.

29. Longoria J, Brown ES, Perantie DC, Bobadilla L, Nejtek VA. Quetiapine for alcohol use and craving in bipolar disorder. J Clin Psychopharmacol. 2004;24:101-102.
30. Brown ES, Nejtek VA, Perantie DC, Bobadilla L. Quetiapine in bipolar disorder and cocaine dependence. Bipolar Disord. 2002;4:406-411.

31. Brown ES, Nejtek VA, Perantie DC, Rajan Thomas N, Rush AJ. Cocaine and amphetamine use in patients with psychiatric illness: a randomized trial of typical antipsychotic continuation or discontinuation. $J$ Clin Psychopharmacol. 2003;23:384-388.

32. Sattar SP, Schultz SK, Arndt S, Soundy T, Petty F. Long-term adjunctive quetiapine may reduce substance use-a preliminary retrospective study. South Dakota Med. 2007;60:439-441.

33. Brown ES, Garza M, Carmody TJ. A randomized, double-blind, placebo-controlled add-on trial of quetiapine in outpatients with bipolar disorder and alcohol use disorders. J Clin Psychiatry. 2008;69: 701-705.

34. Martinotti G, Andreoli S, Di Nicola M, Di Giannantonio M, Sarchiapone M, Janiri L. Quetiapine decreases alcohol consumption, craving, and psychiatric symptoms in dually diagnosed alcoholics. Human Psychopharmacol Clin Exp. 2008;23:417-424.

35. Brown ES, Jeffress J, Liggin JD, Garza M, Beard L. Switching outpatients with bipolar or schizoaffective disorders and substance abuse from their current antipsychotic to aripiprazole. J Clin Psychiatry. 2005;66:756-760.

36. Davis LL, Li X, Garner C, Biladeau J, Ustinov Y, Uezato A. Divalproex ER versus risperidone for bipolar disorder with comorbid substance use disorder. Washington, DC: 161st Annual Meeting of the American Psychiatric Association; May 3-8, 2008.

37. Frye MA, Chirichigno JW, McKowen J, et al. A single-blind evaluation of divalproex sodium vs olanzapine for alcohol abuse relapse prevention in bipolar disorder. Don Cesar Beach Resort, FL: AAAP Annual Meeting and Symposium Dec 7-10, 2006.

38. Brown ES, Beard L, Dobbs L, Rush AJ. Naltrexone in patients with bipolar disorder and alcohol dependence. Depress Anxiety. 2006;23:492-495.

39. Salloum IM, Douaihy A, Cornelius JR, Daley DC, Kelly TM, Kirisci L. Open label randomized pilot study of combined naltrexone and valproate in bipolar alcoholics. Alcohol Clin Exp Res. 2006;30:140A.

40. Reoux JP, Saxon AJ, Malte CA, Baer JS, Sloan KL. Divalproex sodium in alcohol withdrawal: a randomized double-blind placebo-controlled clinical trial. Alcohol Clin Exp Res. 2001;25:1324-1329.

41. Longo LP, Campbell T, Hubatch S. Divalproex sodium (Depakote) for alcohol withdrawal and relapse prevention. $J$ Addict Dis. 2002; 21:55-64.

42. Aliyev ZN, Aliyev NA. Valproate treatment of acute alcohol hallucinosis: a double-blind, placebo-controlled study. Alcohol Alcohol. 2008;43:456-459.

43. Johnson BA, Rosenthal N, Capece JA, et al. Topiramate for treating alcohol dependence: a randomized controlled trial. JAMA. 2007;298:1641-1651.

44. Johnson BA, Rosenthal N, Capece JA, et al; Topiramate for Alcoholism Advisory Board; Topiramate for Alcoholism Study Group. Improvement of physical health and quality of life of alcohol-dependent individuals with topiramate treatment: US multisite randomized controlled trial. Arch Intern Med. 2008;168:1188-1199.

45. Kushner SF, Khan A, Lane R, Olson WH. Topiramate monotherapy in the management of acute mania: results of four double-blind placebocontrolled trials. Bipolar Disord. 2006;8:15-27.

46. Furieri FA, Nakamura-Palacios EM. Gabapentin reduces alcohol consumption and craving: a randomized, double-blind, placebo-controlled trial. J Clin Psychiatry. 2007;68:1691-1700.

47. Mack A. Examination of the evidence for off-label use of gabapentin. J Manag Care Pharm. 2003;9:559-568.

48. Martinotti G, Di Nicola M, Di Giannantonio M, Janiri L. Aripiprazole in the treatment of patients with alcohol dependence: a double-blind, comparison trial vs naltrexone. J Psychopharmacol. 2009;23:123-129.

49. Anton RF, Kranzler H, Breder C, Marcus RN, Carson WH, Han J. A randomized, multicenter, double-blind, placebo-controlled study of the efficacy and safety of aripiprazole for the treatment of alcohol dependence. J Clin Psychopharmacol. 2008;28:5-12. 
50. Dorus W, Ostrow DG, Anton R, et al. Lithium treatment of depressed and nondepressed alcoholics. JAMA. 1989;262:1646-1652.

51. Dilsaver SC, Swann AC, Shoaib AM, Bowers TC. The manic syndrome: factors which may predict a patient's response to lithium, carbamazepine and valproate. J Psychiatry Neurosci. 1993;18:61-66.

52. Petty F. GABA and mood disorders: a brief review and hypothesis. J Affective Disord. 1995;34:275-281.

53. Brambilla P, Perez J, Barale F, Schettini G, Soares JC. GABAergic dysfunction in mood disorders. Mol Psychiatry. 8:721-737.

54. Enoch MA. The role of GABAa receptors in the development of alcoholism. Pharmacol Biochem Behav. 2008;90:95-104.

55. Vargas C, Tannhauser M, Barros HM. Dissimilar effects of lithium and valproic acid on GABA and glutamine concentrations in rat cerebrospinal fluid. Gen Pharmacol. 1998;30:601-604.

56. Zimmer R, Teelken AW, Gündürewa M, Rüther E, Cramer H. Effect of sodium-valproate on CSF GABA, cAMP, cGMP and homovanillic acid levels in men. Br Res Bull. 1980;5(Suppl 2):585-588.

57. Pacchiarotti I, Marzo SD, Colom F, Sanchez-Moreno J, Vieta E. Bipolar disorder preceded by substance abuse: A different phenotype with not so poor outcome? World J Biol Psychiatry. 2007;13:1-8.
58. Haro JM, van Os J, Vieta E, Reed C, Lorenzo M, Goetz I; EMBLEM Advisory Board. Evidence for three distinct classes of 'typical', 'psychotic' and 'dual' mania: results from the EMBLEM study. Acta Psychiatr Scand. 2006;113:112-120.

59. van Rossum I, Haro JM, Tenback D, et al. Stability and treatment outcome of distinct classes of mania. Eur Psychiatry. 2008;23:360-367.

60. Merikangas KR, Akiskal HS, Angst J, et al. Lifetime and 12-month prevalence of bipolar spectrum disorder in the National Comorbidity Survey replication. Arch Gen Psychiatry. 2007;64:543-552.

61. Merikangas KR, Herrell R, Swendsen J, Rössler W, Ajdacic-Gross V, Angst J. Specificity of bipolar spectrum conditions in the comorbidity of mood and substance use disorders: results from the Zurich cohort study. Arch Gen Psychiatry. 2008;65:47-52.

62. Albanese MJ, Clodfelter RC Jr, Pardo TB, Ghaemi SN. Underdiagnosis of bipolar disorder in men with substance use disorder. $J$ Psychiatr Pract. 2006;12:124-127.

63. Brousse G, Garay RP, Benyamina A. Management of comorbid bipolar disorder and alcohol dependence. Presse Med. 2008;37:1132-1137.
Neuropsychiatric Disease and Treatment

\section{Publish your work in this journal}

Neuropsychiatric Disease and Treatment is an international, peerreviewed journal of clinical therapeutics and pharmacology focusing on concise rapid reporting of clinical or pre-clinical studies on a range of neuropsychiatric and neurological disorders. This journal is indexed on PubMed Central, the 'PsycINFO' database and CAS, and is the official

\section{Dovepress}

journal of The International Neuropsychiatric Association (INA). The manuscript management system is completely online and includes a very quick and fair peer-review system, which is all easy to use. Visit http://www.dovepress.com/testimonials.php to read real quotes from published authors. 